\title{
Masa retroperitoneal en paciente varón joven
}

\author{
M. SOLANO REMÍREZ, J. P. VELILLA ALCUBILLA, M. T. ÁLVAREZ FRÍAS, \\ J. GUTIÉRREZ DUBOIS, L. MUNUERA, C. GARCÍA LABAIRU \\ Servicio de Medicina Interna. Hospital de Navarra. Pamplona
}

A RETROPERITONEAL MASS IN A YOUNG PATIENT

\begin{abstract}
RESUMEN
Ante el hallazgo de una masa en retroperitoneo en un paciente joven se debe tener en cuenta entre los diferentes diagnósticos posibles, el tumor de células germinales. Estos tumores aunque son relativamente infrecuentes, constituyendo menos del $1 \%$ de todos los tumores en el sexo masculino, no es raro que debuten con masa retroperitoneal que simulan clínicamente un cólico renal o/y dolor lumbar. Siempre se debería realizar exploración de genitales externos aunque en un porcentaje no despreciable no encontramos masa testicular. Además el pronóstico es favorable, incluso en estadios avanzados, en un alto porcentaje, y poseemos una serie de marcadores tumorales útiles para el diagnóstico y seguimiento. Presentamos el caso de un paciente con clínica de cólico renal y masa retroperitoneal a estudio.
\end{abstract}

PALABRAS CLAVE: Masa retroperitoneal. Neoplasias de células germinales. Seminoma. Hidronefrosis. Cólico renal. Marcadores tumorales.

\begin{abstract}
A tumor of germinal cells should be considered in the differential diagnosis of a retroperitoneal mass in a young patient. Although, this kind of tumors are relatively uncommon, inducing less than $1 \%$ of all the tumors in the masculine sex, very often they may present as a retroperitoneal mass clinically characterized by a lumbar pain that sometimes may simulate a renal colic. Ocassionally, physical examination of the testis may reveal a mass. Moreover, even in advanced stages the prognosis of germ cell tumor is favorable, and there are a series of tumor markers very helpful for the diagnosis and follow up of the tumor. We report a patient with a retroperitoneal mass presenting clinically as a renal colic.
\end{abstract}

KEY WORDS: Retroperitoneal mass. Germ cell tumor. Seminoma. Hydronephrosis. Renal colic. Tumor markers.

Solano Remírez M, Velilla Alcubilla JP, Álvarez Frías MT, Gutiérrez, Dubois J, Munuera L, García Labairu C. Masa retroperitoneal en pacientes varones jóvenes. An Med Interna (Madrid) 2006; 23: 34-36.

\section{INTRODUCCIÓN}

Las neoplasias testiculares son tumores relativamente poco frecuentes, con una incidencia de 1-2 por cada 100.000 habitantes. Se calcula que en global corresponden al 5\% de los cánceres genitourinarios en el varón. La mayoría se diagnostican entre los 20 y 40 años. Son más frecuentes en el testículo derecho. La vía de diseminación más frecuente es la linfática por lo que no es raro que se presenten como forma inicial como masa de retroperitoneo. La presentación extragonadal supone menos del $10 \%$ de los tumores gonadales. En el diagnóstico ante una masa en retroperitoneo en un paciente joven debe pensarse siempre en un tumor de testes, haciendo diagnóstico diferencial con otros procesos que afecten al retroperitoneo como linfoma esclerosante, otros tumores metastásicos (carcinoma de células en anillo de sello ), tumores de partes blandas inflamatorios, fibrosis retroperitoneal idiopática (Enfermedad de Ormond)o fibromatosis mesentérica. El cáncer de testículo se divide ampliamente en tipos seminoma y no seminoma con el fin de facilitar la planificación de tratamientos. Un aspecto importante en el diagnóstico y seguimiento del cáncer de testículo es el uso de marcadores séricos. Actualmente la tasa de curación de los pacientes con seminoma excede el $90 \%$, es por ello que es importante tener siempre en cuenta la presentación inicial de dicho tumor como una masa retroperitoneal.

\section{CASO APORTADO}

Se trata de un varón de 40 años de nacionalidad búlgaro que presenta en los antecedentes personales reflujo gastroesofágico y cardias incompetente, no intervenido quirúrgicamente ni transfundido previamente, de profesión empleado en Carpintería metálica, fumador de 15-20 cig/día y exbebedor moderado hasta hace 4 años. Entre los antecedentes familiares la madre, el padre y un hermano con nefrolitiasis. Había sido visto hacía 21 días antes de ingresar por dolor en flanco derecho con irradiación hacia testículo ipsilateral que se catalogó como probable cólico renal y tratado con analgesia, con

Trabajo aceptado: 31 de mayo de 2005 
evolución favorable; posteriormente comenzó de nuevo con clínica similar acompañada de sensación nauseosa sin fiebre termometrada ni síndrome miccional; no refería pérdida apetito ni peso. Acudió de nuevo a Urgencias donde se realizó ecografía abdominal que describía la presencia de hidronefrosis grado II/IV y una masa en reteroperitoneo derecho de unos 6-7 cm, por lo que fue ingresado para estudio. El paciente refiere dolor en flanco/fosa renal derecha que le irradia hasta teste ipsilateral sin náuseas ni vómitos ni fiebre termometrada. En la exploración únicamente destacaba sucusión renal derecha positiva. ECG a ritmo sinusal a $76 \mathrm{lpm}$; la radiografía de tórax sin alteraciones patológicas significativas. En la analítica de sangre destacaba fibrinógeno $478 \mathrm{mg} / \mathrm{dL}$ (150-450), VSG21 $\mathrm{mm} /$ hora (2-15), urea $52 \mathrm{mg} / \mathrm{dL}$ (10-50), creatinina $1,4 \mathrm{mg} / \mathrm{dL}(0,6-$ 1,2), LDH 446 U/L (0-288), gonadotropinacoriónica humana 7 UI/L (0-5) y alfafetoproteína $2,2 \mathrm{kU} / \mathrm{L}$ (0,5-7). Se realizó TAC abdominopélvica donde se describía en el retroperitoneo medio (entre la aorta y la vena cava inferior) se aprecia un masa de "tejido blando" única de morfología redondeada $(7 \times 5,5 \mathrm{~cm})$ con una densidad uniforme y un área focal de menor atenuación que "engloba" la vena cava inferior y el ureter derecho con una hidronefrosis grado 2; la lesión está bien delimitada y no se aprecian adenopatías ni lesiones satélites acompañantes. Se realiza interconsulta urgente a Urología que realiza nefrostomía derecha. Se realiza biopsia trucut de masa retroperitoneal guiada por ecografía y se manda pieza a anatomía patológica que la informa como una neoformación constituida por células de gran tamaño que se disponen en nidos, con escasa cohesividad y un citoplasma de límites imprecisos, en general finamente vacuolado, los núcleos son redondeados o hendidos, y presentan un gran nucleolo y las células se disponen formando núcleos y están rodeadas de una gran cantidad de células linfoides de pequeño tamaño, correspondientes a linfocitos maduros, siendo las células tumorales positivas para $\mathrm{C}$-Kit, siendo compatible con tumor germinal tipo seminoma clásico. Ante ello se realiza ecografía de testes donde se observa en el teste derecho una lesión nodular-ovoidea, isodensa con halo hipodenso periférico, de $16 \mathrm{~mm}$, situada en la mitad superior y subcapsular anterior, además otro pequeño nódulo hiperecoico próximo de aproximadamente $5 \mathrm{~mm}$ compatible con tumor testicular derecho. Posteriormente se derivó al Servicio de Urología, tras consulta con Oncología, para realizar orquiectomía y pasar posteriormente a realizar ciclos de quimioterapia en el Servicio de Oncología.

\section{DISCUSIÓN}

El cáncer testicular de células germinales es la neoplasia sólida más frecuente en pacientes entre los 20-40 años, constituyendo el 5\% de los tumores genitourinarios en el varón (1). Representa menos del $1 \%$ de todos los cánceres en el sexo masculino, siendo el tumor más común en pacientes jóvenes después de la leucemia y el linfoma. Se describen tres picos de incidencia: en la infancia, entre los 20-40 años y en mayores de 60 años $(2,3)$. Geográficamente presenta una distribución con predominio en los países de Escandinavia, Suiza, Alemania y Nueva Zelanda, siendo su incidencia más baja en Africa y Asia. Es más frecuente en la raza blanca que en la negra (se ha calculado una relación 4-5/1) (4). La presentación extragonadal supone menos del $10 \%$ de los casos, siendo el mediastino y el retroperitoneo donde más frecuentemente se localizan. En su etiopatogenia se han implicado una serie de factores predisponentes siendo la disgenesia gonadal el factor más asociado (5-20\% de pacientes con criptorquidia desarrollan un tumor germinal, influyendo tanto la carga genética (2-4\% presentan cambios de carcinoma in situ) como la localización anómala (la localización abdominal es de mayor riesgo que la inguinal); así mismo en el síndrome de Klinelfelter aumenta la incidencia de tumor germinal de localización mediastínica; también se ha visto aumento de la incidencia en pacientes infectados por VIH tanto en los seropositivos como en los que desarrollan sida (5). En general son más frecuentes en el testículo derecho. Desde el punto de vista histológico se ha visto que suelen manifestar el isocromosoma del brazo corto del cromosoma 12:12p); también se ha implicado en la transformación maligna la pérdida de material genético tipo delección en el cromosoma 12q (9-11). La forma de presentación patológica es de histología mixta en el $40 \%$ casos. La presentación bilateral sincrónica o asincrónica es poco frecuente siendo más frecuente en el tipo seminoma. Histológicamente se han clasificado los tumores germinales en seminomatosos y no seminomatosos, dado que la estirpe histológica confiere mayor valor pronóstico que el grado de diferenciación tumoral $(7,8)$. El seminoma representa el $50 \%$ de todos los tumores germinales, describiéndose 3 tipos: el clásico (aparece en la $4^{\text {a }}$ década), el espermatocítico (supone el 4-7\% de los seminomas, predominando en mayores de 40 años) y la variante anaplásica. Clásicamente la presentación clínica es de dolor testicular difuso (el 10\% de los pacientes que consultan por dolor se debe a hemorragia intratesticular o necrosis), hinchazón y/o dureza. Un 14\% presenta síntomas derivados del tumor metastásico. El diagnóstico de tumor testicular se realiza habitualmente mediante Ecografía, cuya característica típica es la existencia de una masa testicular, a veces con discreta hipoecogenicidad, o alteraciones difusas con microcalcificaciones (6). El 95\% tumores en el testículo corresponden a tumores germinales. La diseminación a distancia se realiza fundamentalmente por vía linfática; los tumores testiculares derechos metastatizan en los ganglios interaortocavos, mientras que los del testículo izquierdo metastatizan en los ganglios paraaórticos a nivel del hilio renal ipsilateral; raramente aparecen metastasis ganglionares contralaterales. Los tumores seminomatosos suelen presentar crecimiento lento con extensión por vía linfática a ganglios retroperitoneales. No es raro que se presenten inicialmente como masa retroperitoneal que se objetiva de forma casual. En el estudio de extensión se debe realizar TAC abdomino-pélvico, radiografía de tórax (si se sospechase afectación mediastínica, hiliar o pulmonar, se debe completar con TAC torácico), gammagrafía ósea si existe dolor tipo óseo o alteraciones analíticas que sugieran metástasis óseas. Si sospecha de metástasis cerebrales, realizar TAC o RMN cerebral (12). Disponemos de marcadores tumorales (alfafetoproteína, LDH y beta-goniotropinacoriónica) que han demostrado un papel en el manejo del diagnóstico (el grado de elevación sérica inicial de estos marcadores influye íntimamente en el pronóstico), pronóstico ( el grado de elevación de estos marcadores antes del tratamiento constituye uno de los factores pronósticos más importantes en los tumores no seminomatosos, a diferencia de lo que ocurre en los seminomatoso), respuesta al tratamiento (la elevación de beta-HCG y/o alfafetoproteína en pacientes con estadio I tratados con orquiectomía o estadios avanzados tratados con quimioterapia, es indicativo de recidiva) y posterior seguimiento en los tumores germinales. La elevación de los niveles séricos de alfafetoproteína es incompatible con el diagnóstico de seminoma puro y siempre refleja la presencia de elementos de tumor no seminomatoso. El 30\% de tumores seminomatoso y el $80 \%$ de los no seminomatosos producen invariablemente algún marcador sérico. La relación Beta-HCG en LCR/Beta-HCG en plasma mayor de 1/40 es sugestiva de diseminación cerebral. La elevación de la LDH se encuentra hasta en el $80 \%$ de los seminomas en estadio avanzado. El tratamiento en estadios iniciales (I, IIA, IIB), tumores hasta con metástasis peritoneales menores de $5 \mathrm{~cm}$ en el diámetro transver- 
sal máximo, se basa en la orquiectomía inguinal radical con ligación inicial alta del cordón espermático, incluyendo ganglios linfáticos pélvicos ipsilaterales, con lo que el $4 \%$ pacientes en estadio I presentan recurrencias y hasta el $10 \%$ de los estadios IIA-IIB. El número y el tamaño de los nódulos linfáticos retroperitoneales tienen importancia pronóstica (13). La mayoría de los estudios retrospectivos expresan recurrencia tumoral de hasta el $35 \%$ cuando existen menos de seis nódulos y, el más grande, es menor de 2 centímetros, y no se encuentra extensión extragonadal del tumor (15). Cuando existe extensión tumoral la recurrencia tumoral llega a ser mayor del $50 \%$. En los estadios tumorales iniciales que presentan recurrencia se realiza tratamiento con quimioterapia consiguiendo curaciones de hasta el $90 \%$ (17). En los tumores en estadio IIC o con MTS se tratan con quimioterapia pudiendo llegar a curaciones del $70-80 \%$ $(14,16,18)$. La extirpación quirúrgica de las masas residuales

\section{Bibliografía}

1. Greenlee RT, Murray T, Bolden S, Wingo PA. Cancer statistics 2000. CA: Cancer J Clin 2000; 50: 7.

2. McKiernan JM, Goluboff E, Liberson G, Golden R, Fisch H. Rising risk of testicular cancer by birth cohort in the United States from 1973 to 1995. J Urol 1999; 162: 361.

3. Bergstrom R, Adami HO, Mohner M, et al. Increase in testicular cancer incidence in six European countries: a birth cohort phenomenon. J Natl Cancer Inst 1996; 88: 727.

4. Schottenfeld D, Warshauer M, Sherlock S, et al. The epidemiology of testicular cancer in young adults. Am J Epidemiol 1980; 112: 232.

5. Timmerman J, Northfelt D, Small E. Malignant germ cell tumors in men infected with the human immunodeficiency virus: natural history and results of therapy. J Clin Oncol 1995; 13: 1291.

6. Renshaw AA. Testicular calcifications: incidence, histology and proposed pathological criteria for testicular microlithiasis. J Urol 1998; 160: 1625.

7. Mostofi FK, Sesterhenn IA. Revised International Classification of Testicular Tumors. In: Jones WG, Harnden P, Appleyard I, eds. Germ cell tumors III. Oxford: Pergamon, 1994: 153.

8. Leibovitch I, Foster R, Ulbright T, Donohue J. Adult primary pure teratoma of the testis. The Indiana Experience. Cancer 1995; 75: 2244.

9. Vogelzang NJ, Shipley WU, Scardino PT, Coffey DS, eds. Comprehensive textbook of genitourinary oncology. Baltimore: Williams \& Wilkins, 1996: 932.

10. Chaganti RSK, Houldsworth J. The cytogenetic theory of the pathogenesis of human adult male germ cell tumors. APMIS 1998;106: 80. retroperitoneales tras quimioterapia, esta indicada cuando midan más de $3 \mathrm{~cm}$.

Podemos concluir que ante el hallazgo casual en una exploración complementaria radiológica de una masa en retroperitoneo en un paciente varón joven siempre deberemos pensar en la posibilidad de que se trate de la presentación primaria o en la extensión de un tumor germinal. Por ello deberíamos realizar una exploración exhaustiva y con ecografía de los testículos para hallar un posible tumor primario. Entre las manifestaciones clínicas de las metástasis retroperitoneales de los tumores germinales suele ser frecuentes el dolor lumbar o de tipo cólico con irradiación a testes ipsilateral. Es importante tener presente el tumor germinal ante una masa retroperitoneal porque el cáncer de testículo es sumamente tratable, generalmente curable (hasta en el $90 \%$ según estadios) y que usualmente se desarrolla en los hombres jóvenes y de edad media.

11. Murty VVVS, Chaganti RSK. A genetic perspective of male germ cell tumors. Semin Oncol 1998; 25: 133.

12. Leibovitch I, Foster R, Kopecky K, Donohue J. Improved accuracy of computerized tomography based clinical staging in low stage nonseminomatous germ cell cancer using size criteria of retroperitoneal lymph nodes. J Urol 1995; 154: 1759.

13. Mencel PJ, Motzer RJ, Mazumdar M, et al. Advanced seminoma: treatment results, survival, and prognostic factors in 142 patients. J Clin Oncol 1994; 12: 120.

14. Bajorin D, Mazumdar M, Meyers M, et al. Metastatic germ cell tumors: modeling for response to chemotherapy. J Clin Oncol 1998; 16: 707.

15. Vaeth M, Schultz HP, von der Maase H, et al. Prognostic factors in testicular germ cell tumors. Acta Radiol Oncol 1984; 23: 271.

16. IGCCCG. International Germ Cell Consensus classification: a prognostic factor-based staging system for metastatic germ cell cancers. J Clin Oncol 1997; 15: 594.

17. Sogani PC, Perrotti M, Herr HW, et al. Clinical stage I testis cancer: long-term outcome of patients on surveillance. J Urol 1998; 159: 855 .

18. Warde P, Gospodarowicz M, Panzarella T, et al. Management of stage II seminoma. J Clin Oncol 1998; 16: 290.

19. Einhorn LH, Williams SD, Loehrer PJ, et al. Evaluation of optimal duration of chemotherapy in favorable-prognosis disseminated germ cell tumors: a Southeastern Cancer Study Group protocol. J Clin Oncol 1989; $7: 387$. 